\title{
Performance Analysis of a Linear Motor with HTS Bulk Magnets for Driving a Prototype HTS Maglev Vehicle
}

\author{
Youguang Guo*, Jianxun Jin**, Jianguo Zhu*, and Haiyan Lu* \\ * University of Technology Sydney, Sydney, Australia \\ ** University of Electronic Science and Technology of China, Chengdu, China
}

\begin{abstract}
This paper presents the performance analysis of a linear synchronous motor which employs hightemperature superconducting (HTS) bulk magnets on the mover and normal copper windings on the stator. The linear motor is designed to drive a prototype HTS maglev vehicle in which the mover is suspended by the levitation force between HTS bulks on the mover and permanent magnets on the ground. Finite element magnetic field analysis is conducted to calculate the major parameters of the linear motor and an equation is derived to calculate the electromagnetic thrust force. Theoretical calculations are verified by the measured results on the prototype.
\end{abstract}

Index Terms--High temperature superconducting (HTS), HTS bulk magnet, HTS maglev, linear synchronous motor.

\section{INTRODUCTION}

Since Hellman et al. reported the phenomenon that a stable levitation force can be produced when an $\mathrm{NdFeB}$ permanent magnet (PM) is placed over a high temperature superconducting (HTS) YBCO bulk bathed in liquid nitrogen [1], strong research interest has been generated about its applications on magnetic levitation (maglev) [2-4]. The first man-loading HTS maglev test vehicle was prototyped in 2000 [2] and many further research efforts, such as system optimization, stability control, and effects of ramp angles and AC fields, were carried out in order to improve the system performance toward practical use [4].

To investigate the application potential of the HTS maglev, the authors of this paper have developed a prototype vehicle as illustrated schematically in Fig. 1 [57]. The interaction between the HTS bulks on the movable body and the PM guideways (PMGs) on the ground generates a strong levitation force with passive and self-stabilizing features. Therefore, such a system would not request a sophisticated control system for the regulation of the air gap between the PMGs and the moving body, which is necessary for other types of maglev transportation systems.

The vehicle is driven by a linear synchronous motor (LSM) with 3-phase copper windings in the primary side (stator) and the HTS bulk magnets placed in liquid nitrogen in the secondary side (mover). The bulk superconductor magnet is also among the many

This work was partly supported by the Chinese High Technological Development Plan Project under Grant No. 2007AA03Z208. application prospects of HTS. The HTS bulks could trap higher magnetic field than PMs and hence possess great potential for applications in compact and high performance electric motors [8-10].

This paper presents the motor performance analysis based on finite element magnetic field analysis and analytical equation. The calculations are validated by experimental results on the prototype.

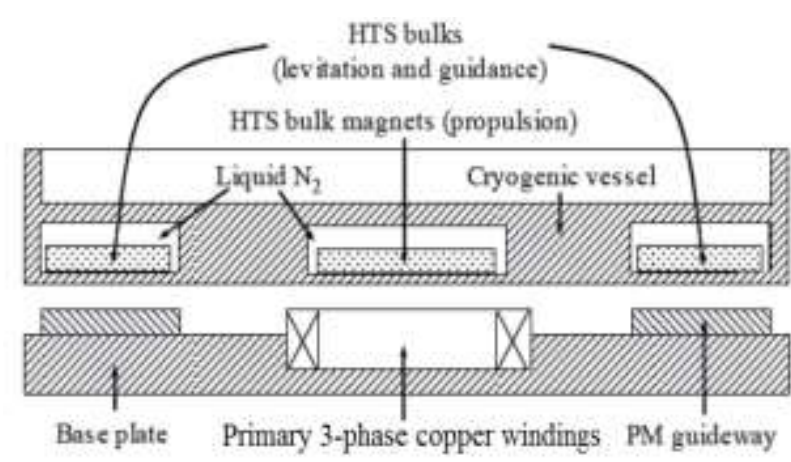

Fig. 1. Schematic diagram of an HTS maglev vehicle

\section{PERformance ANALYSIS OF THE LSM}

\section{A. LSM Structure and Main Dimensions}

The linear motor is composed of the HTS bulk magnets on the bottom of the prototype vehicle and the 3 phase copper windings on the ground. As shown in Fig. 2 , the secondary magnets consist of $6 \times 5=30$ YBCO HTS bulks bathed in liquid nitrogen to form six poles with alternative polarities along the moving direction and five bulks with the same polarity along the transversal direction. The dimensions of each bulk are $37 \mathrm{~mm}$ in length (along the moving direction), $30 \mathrm{~mm}$ in width (along the transversal direction), and $15 \mathrm{~mm}$ in height.

The stator is composed of concentrated copper coils wound around laminated steel teeth. The tooth is of 10 $\mathrm{mm}$ in length (the moving direction) and $150 \mathrm{~mm}$ in width (the transversal direction), and the slot is of $20 \mathrm{~mm}$ in length and $100 \mathrm{~mm}$ in depth. The coils are connected to form a symmetrical three-phase winding, in which the three-phase currents will produce a travelling magnetic field.

The span of the HTS bulk magnets along the moving direction is $45 \mathrm{~mm}$, which equals 1.5 times of the tooth pitch. The magnetization of the bulk magnets was 
realized by using a split pulse coil system as shown in Fig. 3 [11]. For this prototype, bulk magnets with trapped magnetic flux density of $0.5 \mathrm{~T}$ and relative permeability of 0.4 are achieved.

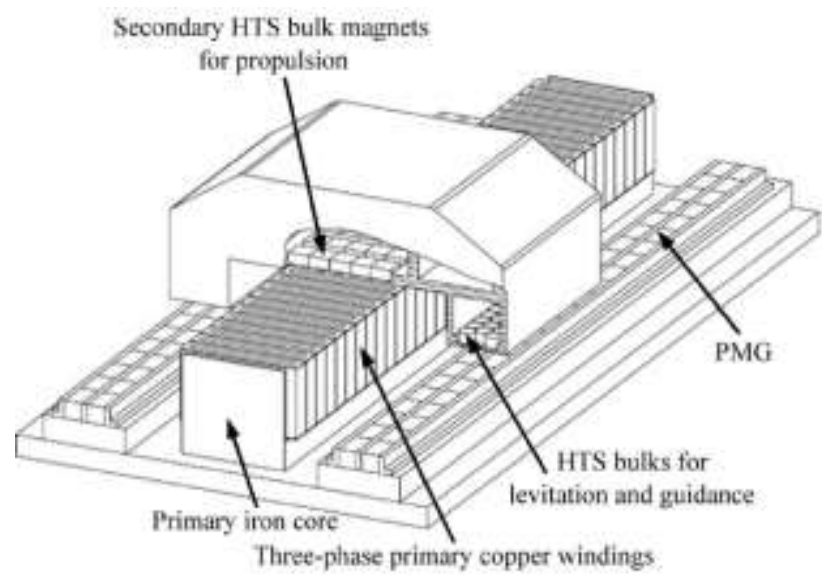

Fig. 2. Schematic diagram of the HTS bulk magnet LSM integrated with HTS bulk-PM maglev

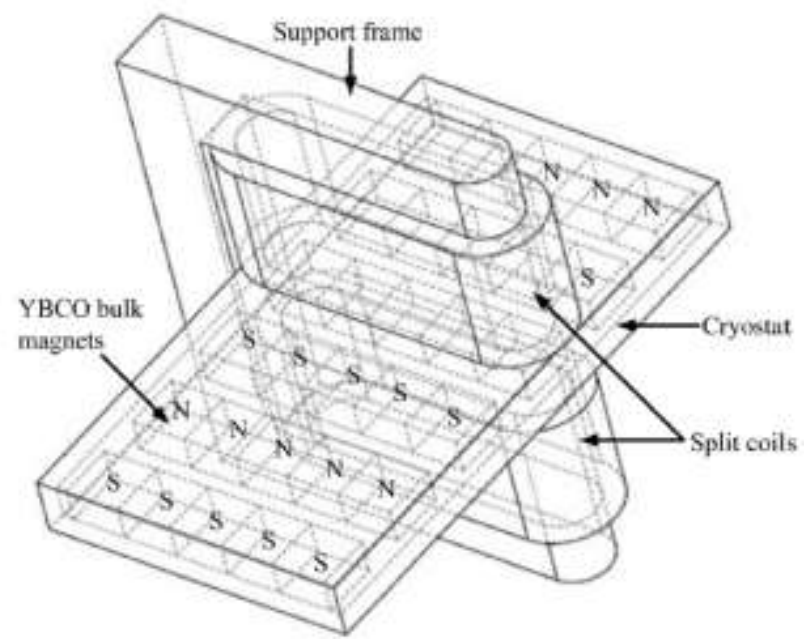

Fig. 3. A split coil system for magnetization of HTS bulk magnets

\section{B. No-load Magnetic Flux Linkage and Back EMF}

Based on the structure and dimensions of the motor, a two-dimensional (2-D) magnetic field finite element analysis (FEA) model is built as in Fig. 4, where the magnetic lines of force generated by the HTS bulk magnets (without stator currents) are also shown. According to the magnetic vector potentials obtained, the flux linkage of each coil and phase winding can be calculated.

When the vehicle moves, the flux linkage of phase winding varies. This variation can be acquired by analyzing the magnetic field distribution at different mover positions for one pole-pair by using time-stepping FEA. When the vehicle runs at a constant speed of 0.45 $\mathrm{m} / \mathrm{s}$, the flux linkages of three phase windings are shown in Fig. 5, which are almost sinusoidal and symmetrical with magnitude of $0.33 \mathrm{~Wb}$ and shifted to each other by 120 electrical degrees.

Due to the variation of flux linkage, a back electromagnetic force (EMF) is produced in the winding and can be calculated by

$$
E_{0}=\sqrt{2} \pi f \lambda m
$$

where $\lambda_{m}=0.33 \mathrm{~Wb}$ is the maximum flux linkage of one phase winding, and $f$ is the back EMF frequency, which is determined by the mover speed as $f=v /(2 \tau)$. For Fig. 5, the mover speed $v=0.45 \mathrm{~m} / \mathrm{s}$, and the pole pitch $\tau=45 \mathrm{~mm}$, so $f$ can be calculated as $5 \mathrm{~Hz}$, and $E_{o}$ is $7.33 \mathrm{~V}$ in rms or $10.4 \mathrm{~V}$ in magnitude.

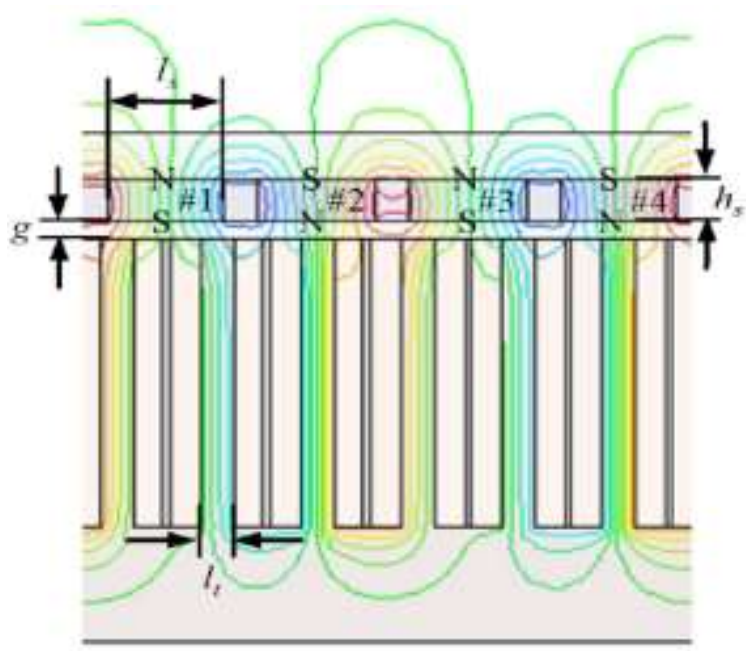

Fig. 4. 2-D magnetic field FEA of the bulk magnet LSM and magnetic force line distribution

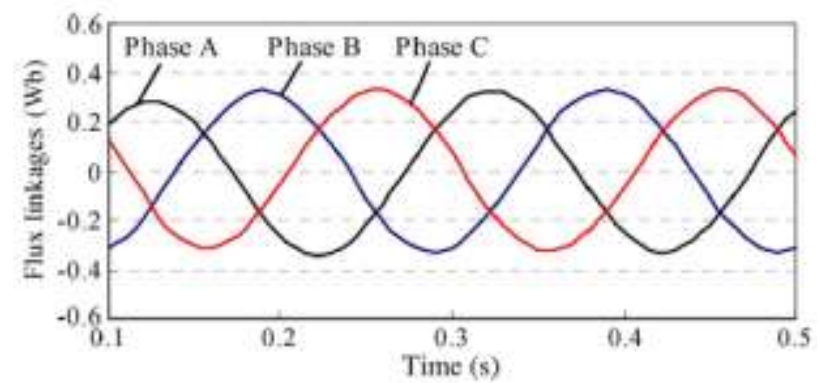

Fig. 5. Flux linkages of phase windings generated by the bulk magnets

\section{Winding Inductance}

The winding inductance can also be worked out based on magnetic field FEA results. An incremental energy method [12] was used to calculate both the self and mutual inductances, which includes two steps: (1) For a given mover position, a nonlinear magnetic field FEA is carried out considering the saturation of stator core due to the bulk magnets, and the incremental permeability in each element is saved. (2) Assume the trapped flux density of the bulk magnets is zero, and conduct a linear field analysis with the saved permeabilities, under perturbed stator current excitations, i.e. assigning the 3 phase winding currents as $\left(i_{a}, i_{b}, i_{c}\right)=(\Delta i, \Delta i, 0),(\Delta i, 0, \Delta i)$, $(0, \Delta i, \Delta i),(\Delta i, 0,0),(0,0, \Delta i)$, and $(0, \Delta i, 0)$, respectively; (3) Calculate the co-energy for each current excitation; and (4) Calculate the incremental inductances by 


$$
\begin{aligned}
& L_{a a}(\theta)=L_{b b}(\theta)=L_{c c}(\theta)=\frac{2 W_{c}(\Delta i, 0,0, \theta)}{(\Delta i)^{2}} \\
& L_{a b}(\theta)=L_{b a}(\theta) \\
& =\frac{W_{c}(\Delta i, \Delta i, 0, \theta)-W_{c}(0, \Delta i, 0, \theta)-W_{c}(\Delta i, 0,0, \theta)}{(\Delta i)^{2}} \\
& L_{b c}(\theta)=L_{c b}(\theta) \\
& =\frac{W_{c}(0, \Delta i, \Delta i, \theta)-W_{c}(0, \Delta i, 0, \theta)-W_{c}(0,0, \Delta i, \theta)}{(\Delta i)^{2}} \\
& L_{c a}(\theta)=L_{a c}(\theta) \quad W_{c}(\Delta i, 0, \Delta i, \theta)-W_{c}(0,0, \Delta i, \theta)-W_{c}(\Delta i, 0,0, \theta) \\
& =\frac{(\Delta i)^{2}}{}
\end{aligned}
$$

It is found that the inductances do not vary much against mover position, $\theta$.

\section{Thrust Force}

The linear motor has a long primary stator and its stator resistance should be included in the calculation of motor performance [13]. The electromagnetic thrust can be derived as

$$
F_{e m}=\frac{m I_{1} E_{0}\left(R_{1}^{2}+X_{t}^{2}\right)^{3 / 2} \sin (\theta+\phi)-m E_{0}^{2} R_{1}}{2 \nVdash f\left(R_{1}^{2}+X_{t}^{2}\right)}
$$

where $R_{l}$ is the phase winding resistance, $X_{t}$ the synchronous reactance, $I_{l}$ the stator current, $m=3$ the number of phases, $\theta$ the load angle, and $\phi=\tan ^{-1}\left(R_{l} / X_{t}\right)$ the load shift angle. When $\theta+\phi=90^{\circ}$, the maximum thrust force $F_{\text {em_max }}$ is obtained. Fig. 6 shows the calculated $F_{\text {em_max }}$ with respect to different stator currents when the current frequency is $5 \mathrm{~Hz}$. For comparison, the simulations based on FEA and the measurements are also given, showing good agreement.

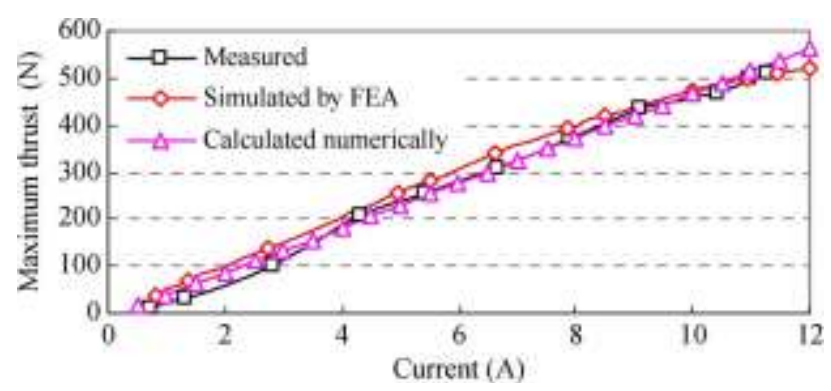

Fig. 6. Calculated and measured maximum thrust force with respect to stator current when $f=5 \mathrm{~Hz}$

\section{EXPERIMENTAL VALIDATION}

To validate the analysis and calculation of the HTS maglev system and the linear motor drive, an experimental platform has been set up. Fig. 7 shows the photo of the HTS maglev prototype which can be levitated by the interactions of HTS bulks bathed in liquid nitrogen and PMs, so that there is little friction force when the mover moves.

The linear motor is operated under a closed loop speed control based on voltage space vector pulse-widthmodulation. Fig. 8 shows the measured three-phase currents when $v$ is controlled to be $0.45 \mathrm{~m} / \mathrm{s}$ and $U / f=15$ Vs, where $U$ is the applied phase voltage. It can be seen that the waveforms of three phase currents are almost sinusoidal and shifted by $120^{\circ}$ electrical to each other.

To measure the back EMF, another linear motor is used to drive the tested motor at a constant speed of 0.45 $\mathrm{m} / \mathrm{s}$ and the measured three-phase back EMFs (open circuit voltage) are depicted in Fig. 9. It can be found that the three-phase back EMFs are almost sinusoidal and three-phase balanced. The magnitude of back EMF is about $10.9 \mathrm{~V}$, which agrees with the calculated value by (1). The EMF waveform has a period of $0.2 \mathrm{~s}$, or a frequency of $5 \mathrm{~Hz}$.

To measure the thrust force, a measurement system is set up as in Fig. 10, which can measure both the thrust force and the attraction force. The measured maximum thrust forces under different stator currents are shown Fig. 6, matching well with the calculations.

The attraction force between the mover and the stator is unwanted but unavoidable for the single-sided linear motor. To eliminate this drawback, the double-sided structure of linear motor may be considered [7].

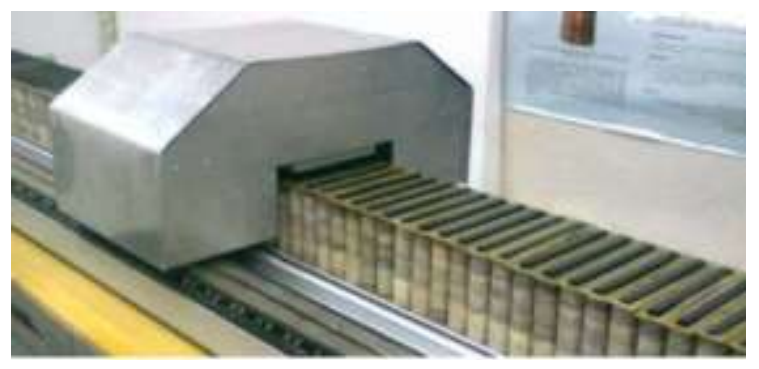

Fig. 7. Photo of the HTS maglev vehicle prototype

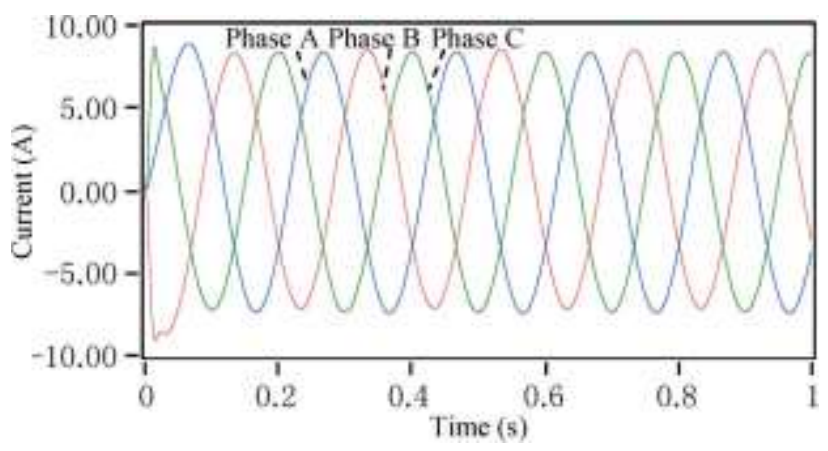

Fig. 8. Measured phase currents when $f=5 \mathrm{~Hz}$ and $U / f=15 \mathrm{Vs}$

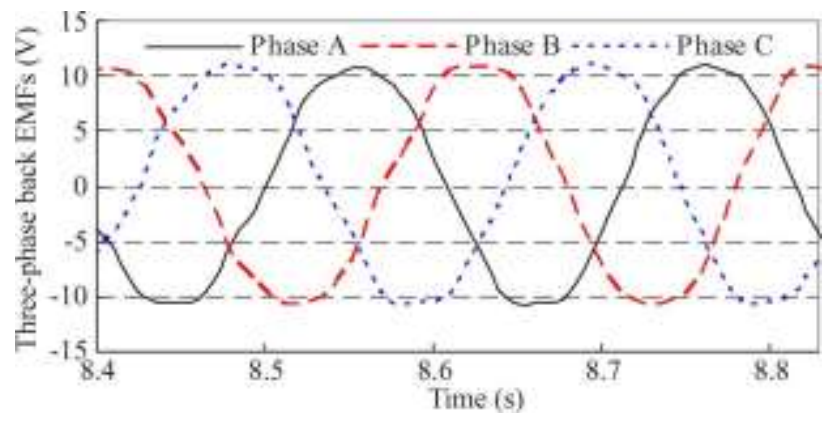

Fig. 9. Measured three phase back EMFs at mover speed of $0.45 \mathrm{~m} / \mathrm{s}$ 


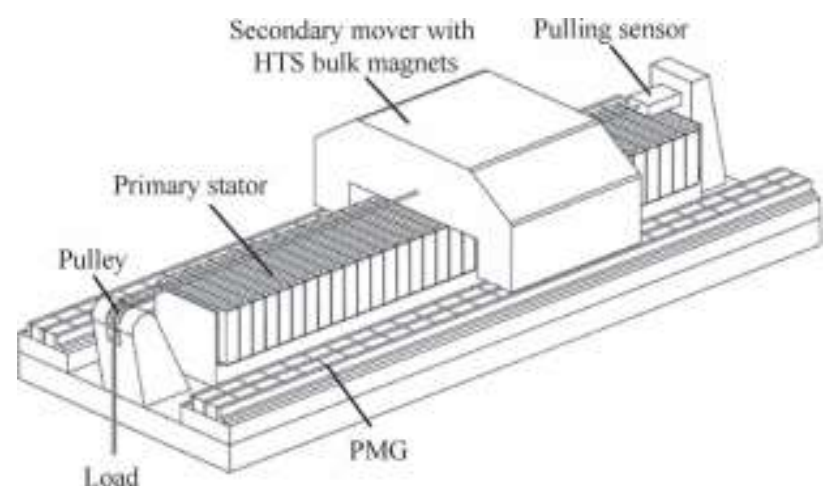

Fig. 10. Thrust force measurement system of the linear motor

\section{CONCLUSIONS}

This paper presents the performance analysis and experimental validation of a linear synchronous motor with HTS bulk magnets in an HTS maglev vehicle prototype. The analysis and experimental results show that the HTS technologies including bulk magnets and magnetic suspension have great potential for application in transportation systems.

\section{REFERENCES}

[1] F. Hellman, E. M. Gyorgy, D. W. Johnson Jr., H. M. O'Bryan, and R. C. Sherwood, "Levitation of a magnet over a flat type II superconductor," J. Appl. Phys., vol. 63, pp. 447-450, Jan. 1988.

[2] S. Wang, J. Wang, X. Wang, Z. Ren, Y. Zeng, C. Deng, H. Jiang, M. Zhu, G. Lin, Z. Xu, D. Zhu, and H. Song, "The man-loading high-temperature superconducting maglev test vehicle," IEEE Trans. Applied Superconductivity, vol. 13, no. 2, pp. 2134-2137, June 2003.

[3] H. W. Lee, K. C. Kim, and J. Lee, "Review of maglev train technologies," IEEE Trans. Magn., vol. 42, no. 7, pp. 1917-1925, July 2006.

[4] J. Wang, S. Wang, J. Zheng, F. Yen, G. Ma, L. Liu, J. Li, and W. Liu, "Recent Developments of the high temperature superconducting maglev at ASCLab," IEEE Trans. Applied Superconductivity, vol. 21, no. 3, pp. 15511555, June 2011.
[5] L. H. Zheng, J. X. Jin, Y. G. Guo, H. Y. Lu, and J. G. Zhu, "Design and electromagnetic analysis of a HTS linear synchronous motor," Proc. of IEEE Int. Conf. on Applied Superconductivity and Electromagnetic Devices, Sep. 2009 , Chengdu, China, pp. 5-10.

[6] J. X. Jin, L. H. Zheng, Y. G. Guo, and J. G. Zhu, "Performance characteristics of an HTS linear synchronous motor with HTS bulk magnet secondary," IEEE Trans. Industry Applications, vol. 47, no. 6, pp. 2469-2477, Nov./Dec. 2011

[7] J. X. Jin, L. H. Zheng, Y. G. Guo, J. G. Zhu, C. Grantham, C. C. Sorrell, and W. $\mathrm{Xu}$, "High-temperaturesuperconducting linear synchronous motors integrated with HTS magnetic levitation components," IEEE Trans. Applied Superconductivity, vol. 22, no. 5, p.5202617, Oct. 2012.

[8] S. Gruss, G. Fuchs, G. Krabbes, P. Verges, P. Schatzle, K. Muller, J. Fink, and L. Schultz, "Trapped fields beyond 14 Tesla in bulk $\mathrm{YBa}_{2} \mathrm{Cu}_{3} \mathrm{O}_{7-\delta}$," IEEE Trans. Applied Superconductivity, vol. 11, no. 1, pp. 3720-3723, Mar. 2011.

[9] G. Stumberger, M. T. Aydemir, D. Zarko, and T. A. Lipo, "Design of a linear bulk superconductor magnet synchronous motor for electromagnetic aircraft launch systems," IEEE Trans. Applied Superconductivity, vol. 14, no. 1, pp. 54-62, June 2011.

[10] X. Feng, G. Gao, K. Davey, M. Werst, R. Hebner, R. Weinstein, D. Parks, and R. Sawh, "Radial flux high temperature superconductor motor using bulk trapped field magnets," Proc. of IEEE Int. Electric Machines and Drives Conf., May 2009, Miami, USA, pp. 458-464.

[11] J. X. Jin, L. H. Zheng, W. Xu, Y. G. Guo, and J. G. Zhu, "Influence of external traveling-wave magnetic field on trapped field of a high temperature superconducting bulk magnet used in a linear synchronous motor," J. Appl. Phys., vol. 109, no. 6, p.113913, 2011

[12] Y. G. Guo, J. G. Zhu, and H. Y. Lu, "Accurate determination of parameters of a claw pole motor with SMC stator core by finite element magnetic field analysis," IEE Proceedings - Electric Power Application, Vol. 153, No. 4, pp. 568-574, July 2006.

[13] Z. Deng, I. Boldea, and S. Nasar, "Forces and parameters of permanent magnet linear synchronous machines," IEEE Trans. Magn., vol. 23, no. 1, pp. 305-309, Jan. 1987. 